changes in the number and arrangement of plates; the increasing complication of the ammonite sutures is explained on the same ground. It is pointed out that the multiplication in number of the sinupalliate Lamellibranchiata in Cretaceous time and their further acceleration in company with the Heterodont forms in the Tertiary period correspond with the incoming and continuance of freshwater conditions. In recent times certain Lamellibranch species in the Black Sea and Caspian Sea have wandered into brackish and fresh water, and as a result there is an increase in length of the siphon, a gaping of the shell, and the formation of a mantle-sinus.

The work has been written in the seclusion of an Indian hotel without the immediate advantages of close contact with the scientific world and its literature. This explains to a great extent the semi-popular nature of the book, and accounts, perhaps, for the omission of a bibliography other than rare and general references in the text. A division into chapters and the inclusion of a more extensive index would have been a decided improvement. Although controversial in many of its statements, the contribution has the undoubted merit of arousing interest and thought. The author appears to be a strong believer in the inheritance of acquired characteristics, and is not inclined to the assumption of an indwelling tendency towards perfection in forms of life; the followers of Cope, von Baer, Naegeli, and von Eimer would, therefore, find much material for debate. The statement that land or fresh-water animals and plants older than of Tertiary age are not found in the earth clefts of primary and secondary formations is certainly erroneous. For instance, the teeth of Microlestes found by Charles Moore and submitted to Owen in $185^{8}$ came from a Rhaetic breccia filling a fissure in the mountain Limestone, near Frome, Somersetshire.

Ivor Thomas.

\section{COMMERCIAL ORGANIC ANALYSIS.}

Allen's Commercial Organic Analysis. Edited by Prof. H. Leffmann and W. A. Davis. Vol. II., Fixed Oils, Fats and Waxes, Soap, Glycerol, Cholesterols, \&c. Fourth edition, entirely rewritten. Pp. $x+520$. (London: J, and A. Churchill, IgIo.) Price 2 I $s$. net.

M OST analysts are aware that a fourth edition of W Allen's well-known work is in course of preparation. Two of the eight volumes composing the edition have now appeared, and a notice of Vol. I. will be found in NATURE of June 16 last. Two more are announced for publication this year, and the remaining four are promised without undue delay. The plan of having both an American and an English editor has been adopted, and articles are contributed by writers from each side of the Atlantic. This seems a sensible arrangement, as with comparatively little modification the book is made to serve the needs of chemists in both countries.

The volume now under review is much extended and improved as compared with its predecessor of the last edition. Mr. C. A. Mitchell is responsible for the opening section describing the general properties of the fixed oils and fats, as well as the common processes of analysis, whilst the special characters of the individual products, and the particular methods of examining them, are discussed by Mr. L. Archbutt. Having regard to the scope of the book, both sections appear to be very well done. As much trustworthy information as could well be given in the space allotted will be found in these two sections, and no point of importance calling for adverse remark has been noticed by the present writer in looking through a number of representative pages. Perhaps the articles on arachis oil, olive oil, and the beeswax group may be singled out as good examples of compressed essentials. Sometimes, indeed, the compression is a trifle too marked. Many references, however, are given to original papers, so that fuller details can often be obtained.

Certain products, including butter, soap, and glycerol, are each given a special section. Messrs. Revis and Bolton have taken charge of the chapter on butter fat. They have studied their subject well, and, among other things, have grasped a fact which seems to have puzzled some experts on butter analysis -namely, that the addition of lard to butter may produce a distinct (apparent) increase of the "Polenske figure," which might be taken by the unwary as indicating the presence of cocoanut oil. One or two small errors have crept in; thus the Zeiss values in the first table on p. 290 are wrongly given as being taken at $40^{\circ} \mathrm{C}$. instead of $45^{\circ}$, and there are two misprints in the second table on the same page. A favourable opinion, based upon the authors' own experiments, is expressed in reference to Lallemant's "barium saponification" method of examining butter fat. How far the commendation is deserved cannot be judged from the particulars given. For example, granted that the method detects cocoanut oil in butter, it may yet be that the detection could be made just as certainly and much more readily by older processes. The really difficult problem is the recognition of lard or beef-fat when present in butter, and it is in the promise of this that the chief importance of Lallemant's process lies. It will be interesting to see how it stands the test of experience when applied, on a sufficiently extended scale, to genuine butter having Reichert-Wollny values in the region of 23 and 24 .

Of Prof. Leffmann's chapter on soaps and the other special contributions it must suffice to note that they contain all that an analyst will generally require to know on the subjects. They help to make the volume a distinct improvement upon the former editions.

C. S.

THE SEVEN LAMPS OF BIOLOGY.

Das System der Biologie in Forschung und Lehre. Eine historisch-kritische Studie. By Dr. Phil. S. Tschulok, Zürich. Pp. $\mathrm{x}+4$ og. (Jena: Gustav Fischer, I910.) Price 9 marks.

THE author discusses at great length some of the attempts that have been made to define the scope of biology, and to indicate the logical sub-divisions of the science. Starting with early workers like Ray,

$$
\text { NO. } 2 \text { I } 4 \text { I, VOL. 85] }
$$


he works on to A. P. De Candolle and Schleiden (of whose importance he is very appreciative), and thence to Haeckel and Spencer, Karl Pearson, and Burckhardt. This laborious historical survey, which must have cost the author much time and trouble, is interesting to those who care for such questions, but it seenis to us to be robbed of some of its value by being overloaded and by a lack of perspective. Dr. Tschulok quotes classifications of the different departments of biology from a large number of text-books, some of which are rather humdrum performances, while others are by men who left a deep mark on the science, but had neither any particular interest in mapping out its subdivisions, nor any special aptitude for so doing.

To illustrate, a man like Burckhardt was a good zoologist-too early lost to science-but he was also a philosopher. He went the length of thinking about the classification of the sciences, about the relation of biology to other disciplines, about methodology, and so on, his writings sometimes reminding us of those of Prof. Patrick Geddes in this country. Naturally, therefore, we are glad to have from Dr. Tschulok an cxposition of Burckhardt's views, and we are especially grateful for the unearthing of an essay on the histrry of biological "Systematiks," well-buried "an einem ziemlich versteckten Orte." But what we regret is the space that is given to what are really incompetent classifications. The author wearies us with citations from manuals of botany, which start with commonplace mappings out of the science, sometimes beginning with a weird word like "Glossology," and ending up with "Fossil Botany." The last is a careless usage, which in an interesting irony sometimes justifies itself. Our regret that the author has been at such pains to expose the nakedness of the land is heightened when we find that he has missed most of the few really illuminating British contributions to the subject of his book. We may refer, for instance, to well-known encyclopadia articles by Prof. Patrick Geddes and Sir E. Ray Lankester.

The author divides biology into Biotaxis and Biophysik. The first has to do with the establishment of conceptual relations, the second with the establishment of real relations-causal and teleological. Classification. for instance, is "biotactic"; physiological analysis is "biophysical." He contrasts his dual division with others, e.g., with morphology and physiology (which is a "scholasticism," he says), or with biostatics and biodynamics, which expresses a different idea. But does Dr. Tschulok mean more than this, that we have in biology, as elsewhere, to discover the orderliness of sequences and to sum this up in conceptual formulæ?

The author's chief contribution is a scheme of the subdivisions of biology. His idea is that there are seven kinds of inquiry which are individually indispensable and collectively exhaustive. These are: taxonomy, morphology, physiology, œcology, chorology, chronology, and genetics. This appears to us to illustrate most of the vices of classification, such as overlapping, cross-division, and inequality of values. It appears to us, for instance, that taxonomy and NO. 2 I 4 I, VOL. 85 ] morphology are inseparably bound together; that ceology, as Semper said, is part of physiology; that chorology is not an independent division of the science; and so on. It must be noted, however, that Dr. Tschulok defends his seven-fold classification with enthusiasm and learning.

J. A. T.

\section{A MONOGRAPH OF THE PETRELS.}

A Monograph of the Petrels (Order Tubinares). By F. Du Cane Godman, F.R.S. With handcoloured plates by J. G. Keulemans. Part iv., pp. 233-296; part v., pp. 297-38I $+1 v$. (London : Witherby and Co.) Price I5l. ${ }_{15} s$. , bound in full morocco.

THE fourth and fifth parts of the "Monograph of the Petrels," completing this beautiful and valuable work, have been received, and the whole work can now be had, bound in full morocco, price fifteen guineas. It contains 436 pages printed on rag paper, and over one hundred hand-coloured plates by Keulemans, our best ornithological artist. In every respect this beautiful volume has been produced in the best possible style. Nor is the letterpress any less excellent. The work was projected, if not actually begun, by the late $O$. Salvin, who wrote the "Tubinares" for the British Museum catalogue of birds, and the author has endeavoured to carry out the work on the lines laid down by Salvin, taking the catalogue as his guide. The final part contains a masterly introduction to the order Tubinares, a systematic list of species, a classification and key to the genera and species, and an essay by Mr. Pycraft on the systematic position of the petrels.

Petrels apparently belong to an ancient race of birds, as their remains have been found in a fossil state in various parts of the world, mostly in superficial deposits, one species, however, being known from the Red Crag of Norfolk. In external appearance the families of petrels differ in an extraordinary manner, and the species vary in size from the tiny storm petrel to the wandering albatross. Notwithstanding their wide differences, petrels may at once be distinguished from all other birds by their prominent tubular nostrils and by their bills, which consist of several horny pieces separated by deep grooves. They are dispersed throughout the oceans of the world, penetrating to the ice barrier at both Poles, though they are more numerous in the southern than in the northern hemispheres. They are oceanic wanderers, and, unless storm-driven, seldom, if ever, come to land except for the purpose of breeding.

The two parts now before us comprise the rest of the genus Ostrelata, and the genera Pagodroma (the snowy or ice petrel) Bulweria, Macronectes (the "stinker or Nelly" of the sailors), Fulmarus, Daption (the well-known "Cape Pigeon"), Halobæna, and Prion, completing the family Puffinidæ; the lamily Pelecanoididæ comprising one curious genus; and the family Diomedeidæ (the albatrosses), comprising the genera Diomedea, Thalassogeron, and Phcebetria. Certainly the most curious and perhaps the most interesting of all these are the strange little 